\title{
Erratum to: Distribution and ecology of Hemimysis anomala, the latest invader of the Great Lakes basin
}

\author{
Jérôme Marty • Kelly Bowen • Marten A. Koops • \\ Michael Power
}

Published online: 29 March 2011

(C) Springer Science+Business Media B.V. 2011

\section{Erratum to: Hydrobiologia (2010) 647:71-80 DOI 10.1007/s10750-009-9990-7}

In the above mentioned publication, the relationships for body length versus wet and dry weight should be replaced by the following equations:

Wet weight $(\mathrm{mg})=0.02482 \times$ Length $(\mathrm{mm})^{2.8936}$

and

Dry weight $(\mathrm{mg})=0.006482 \times$ Length $(\mathrm{mm})^{2.7511}$

Changes in equation coefficients do not affect any of the statistics or Fig. 3 presented in the original version of the article.

The online version of the original article can be found under doi:10.1007/s10750-009-9990-7.

J. Marty $(\bowtie)$

St. Lawrence River Institute, 2, Belmont Street, Cornwall, ON K6H 4Z1, Canada

e-mail: jmarty@riverinstitute.ca

K. Bowen · M. A. Koops

Great Lakes Laboratory for Fisheries and Aquatic

Sciences, Fisheries and Oceans Canada, 867 Lakeshore

Road, Burlington, ON L7R 4A6, Canada

J. Marty · M. Power

Biology Department, University of Waterloo, 200

University Ave. West, Waterloo, ON N2L 1G3, Canada 